\title{
THE BIOLOGY OF TRICHADENOTECNUM ALEXANDERAE SOMMERMAN (PSOCOPTERA: PSOCIDAE). III. ANALYSIS OF MATING BEHAVIOR
}

\author{
By B. W. BETZ

\section{INTRODUCTION}

Several authors have described mating behavior in species of Psocoptera (Pearman 1928, Sommerman 1943a, 1943b, 1944, 1956, Badonnel 1951, Thornton and Broadhead 1954, Klier 1956, Mockford 1957, 1977, Broadhead 1961, Eertmoed 1966). Only one or at most a few matings in a species were observed. This paper presents a comprehensive analysis of pre- through post-copulatory behavior in Trichadenotecnum alexanderae Sommerman. Evidence is presented for a sex-attractant pheromone, produced only by females that were receptive to mating.

Trichadenotecnum alexanderae is a relatively common psocid in eastern United States (Betz 1983a). The species inhabits trees and rock outcroppings providing its principal food source, pleurococcine algae. Betz (1983a) found that $T$. alexanderae is capable of facultative thelytoky. Formerly, the species was confused morphologically with three other species, all obligatorily thelytokous, which have been identified and described as $T$. castum Betz, $T$. merum Betz, and T. innuptum Betz (Betz 1983a).

This paper is part of a series (cf. Betz 1983b, c, d) detailing the life history of $T$. alexanderae.

\section{Materials AND Methods}

Cultures of $T$. alexanderae were obtained from three populations in Illinois: at Moraine View State Park (McLean County), along the Sangamon River at Lake of the Woods (Champaign County), and along the Salt Fork River at Champaign County Forest Preserve District-Homer Lake (Champaign County).

Specimens were collected from tree trunks with an aspirator and kept with pieces of bark in cotton-stoppered test tubes. Cultures were transported to the laboratory over ice-water in a cooler.

\footnotetext{
11000 North Lake Shore Drive, Chicago, Illinois, 60611.

Manuscript received by the editor August 16, 1982.
} 
Laboratory cultures were kept in cotton-stoppered test tubes. Each tube was supplied ad libitum with food in the form of pleurococcine algae on bark. Culture tubes were stored in closed, glass desiccator jars over a saturated potassium chloride $(\mathrm{KCl})$ solution to maintain a relative humidity of $80 \pm 5 \%$. The temperature regimen for rearing was $23.3^{\circ}: 18.0^{\circ} \mathrm{C}$ light:dark, and the photoperiod was 15 $\mathrm{h}$ light: $9 \mathrm{~h}$ dark. Illumination was 4300 lumens $/ \mathrm{m}^{2}$, supplied by incandescent and fluorescent lamps.

Because the other species of the $T$. alexanderae complex are obligatorily thelytokous and often occur sympatrically with the biparental species, I began a laboratory culture of $T$. alexanderae from each locality with females mated in the laboratory to assure the identity of the culture as the biparental species. Several breeding pairs were used to begin a culture, an attempt to represent the genetic diversity of the original sample from the field population. I also examined the morphology of the original breeding pairs to verify that they were $T$. alexanderae. I used bark obtained only from the original field locality in cultures; bark was examined for eggs before it was placed in a culture.

Mating behavior was studied in adults from Lake Dawson, Lake of the Woods, and Salt Fork cultures. Adults were isolated as late stage nymphs and reared in shell vials (four dram size). Each vial was supplied with a flat piece of bark which lessened the interference of the substrate on mating behavior. Females were 2-3 days old and males were 2-5 days old when brought together, the times when they were the most receptive to mating (Betz 1983c). Isolated specimens were brought together by the following method. The cotton stopper on each vial was removed, the open ends of pairs of vials were apposed, and the vials were tilted carefully until the piece of bark in the vial containing a male contacted the bark in the vial containing a female. The open ends of pairs of vials were kept together and the vials were not moved during observation of the insects. The method I used to bring together isolated specimens did not appear to disturb the insects greatly, and thus probably provided accurate observations of courtship behavior.

\section{RESULTS}

\section{Precopulatory Behavior}

The behavior of male and female $T$. alexanderae was somewhat variable among the successful matings $(N=99)$ and the unsuccessful 
attempts $(\mathrm{N}=45)$ I observed. Most precopulatory behavior followed the patterns outlined in Figure 1.

When bark bearing an isolated, receptive female was brought together with bark bearing a sexually active male, the male always ran onto the female's bark. A male displayed a higher level of activity under these conditions than if his piece of bark was brought together with bark bearing a nymph, a female of $T$. alexanderae in an unreceptive state, or a piece of bark without an insect $(N=7)$. In five of the mating encounters I observed, the male flew onto the female's bark before the two pieces of bark were touching.

This higher level of activity in males occurred even if females were placed out of the males' sight. Almost immediately after a male ran onto the bark of a female, he began a search over the substrate. Sometimes a female remained motionless during this search, even though she might have been active prior to the introduction of a male. The manner in which males elicited this reaction of females remains unknown, although the reaction may have resulted from the slight disturbance caused by the introduction of pieces of bark into the females' vials.

A male searched in the direction of a female, often stopping momentarily to flick his antennae and adjust his course.

When a male approached within about $1 \mathrm{~cm}$ of a receptive female he began a quick, sideways gait while moving toward her, even though she may have remained hidden from the male's view. The sideways gait lasted about 1-2 seconds. Occasionally a male approached a receptive female, or courted her, without the sideways gait $(\mathrm{N}=12)$. Females always fled from these encounters. When a female fled, a male remained in the vicinity of the encounter and spun completely around one or more times flicking his antennae. Then a male usually ran off in the general direction of a female's flight. Unless unsuccessful courtship occurred many times (usually the result of a male not performing the sideways gait), a female would always acquiesce at the next courting.

After performing the sideways gait, a male ran up to a female's side, about midway along her length; a male approached a female almost perpendicularly from her side. If features on the substrate made a male's approach difficult, his contact with a female was as perpendicular to her as the substrate permitted. When a male ran up to a female, he touched her briefly (less than a second) with both his antennae. A male's antennae usually struck a female's thorax or head and the distal end of her forewing because his antennae were 


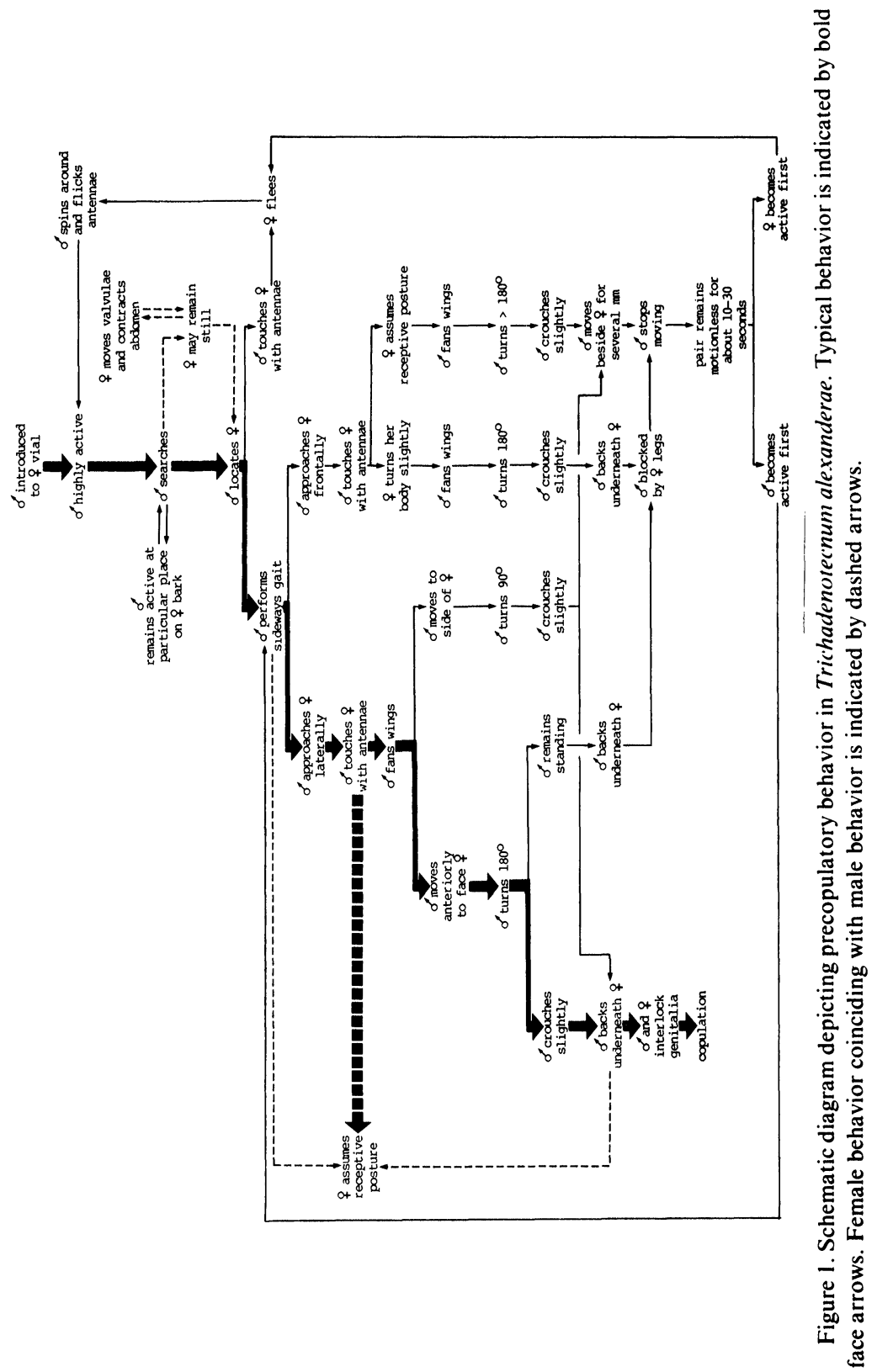


usually held about $90^{\circ}$ apart and at about $45^{\circ}$ off the substrate at rest and also during the search for a female. Directly after contacting her, a male backed away slightly, then rapidly fanned his wings over his body. The wings were fanned at such a rapid rate and at such a small angle (never more than $90^{\circ}$ ) that they became blurred. As a male continued to fan his wings, he began to move anteriorly along a female's side, while still remaining perpendicular to her. A male continued this motion until he was almost facing a female. When this occurred, a male stopped fanning, dropped his wings slightly, turned about $180^{\circ}$, and backed underneath a female between her legs. The genitalia were apposed in this manner.

Occasionally a male stopped fanning when he was only laterally apposed to a female's head, then turned about $90^{\circ}$, and tried to back under her. Of the 14 mounting attempts I observed progressing in this way, only two of them led directly to copulation. Of the failed attempts, eight were unsuccessful because males were blocked from backing in by females' legs; in the remaining four attempts, males turned around farther than necessary and kept moving backward beside the females rather than beneath them.

When a female remained hidden from a male's view, he sometimes approached her directly from the front $(\mathrm{N}=3)$. In two encounters, the female assumed the receptive posture (see below) as the male fanned his wings. However, both of these males were unable to locate the female after they turned around and began to move backwards. One of the males approached the female on her left, turned counterclockwise about $240^{\circ}$, and finally stopped after moving $8 \mathrm{~mm}$ away from her. He then tried to mount her end-to-end (i.e., facing away from her), but this failed. The pair remained motionless in the end-to-end position for about 30 seconds with their genitalia nearly touching, then the male courted the female from her side and was able to orient himself correctly.

The male of the third encounter courted frontally, but the female turned her body slightly instead of assuming the receptive posture, and the male was unable to move far enough backward for their genitalia to come together. The courtship did not lead to copulation.

Most (73.7\%) courting attempts were successful on the first try (Table 1, A). When an attempted mounting failed, a male and female always remained motionless for about 10-30 seconds. After this period, if a male and female remained within about $1 \mathrm{~cm}$ after 
Table 1. Precopulatory behavior in Trichadenotecnum alexanderae

A. Number of courting attempts by a male (including the one leading to copulation)

\begin{tabular}{lr} 
& $\%$ of Total \\
1. One & 73.7 \\
2. Two & 15.2 \\
3. Three & 10.1 \\
4. Four & 0.0 \\
5. Five & 1.0 \\
\hline $\mathrm{N}=99^{\mathrm{a}}$ & 100.0
\end{tabular}

B. Length of time between the introduction of a male and the beginning of mating (i.e., genitalic contact)

$\overline{\mathbf{x}}$

s.d. range $\mathbf{N}$
1.1 minutes 1.3

0.1-9.0 minutes 62

C. Stage in courtship when a female assumed the receptive posture

1. During the approach of a male

2. When touched by a male's antennae

3. Just before a male backed underneath $\mathrm{N}=96$

a The number of mating pairs for which the states of this behavioral character were recorded.

they separated, a male courted again by approaching a female on her side, touching her with his antennae, and fanning his wings. Once either sex had fled from an unsuccessful courtship. males always began further courtship with a sideways gait.

I observed the behavior of females that had fled from a failed courtship $(\mathrm{N}=4)$. Each female eventually stopped moving, and at this time I observed each female flexing her valvulae dorsoventrally in a pairwise manner, and making about ten contractions of her abdomen.

The time required by males to establish genitalic contact after they were introduced to females varied among mating encounters (Table 1, B). This period was usually less than 1 minute if the first courtship was successful. A male ran directly to a female in some encounters, and the time between introduction and the beginning of copulation was usually less than 30 seconds. Some males $(N=5)$ were slower to find females because each remained within à small 
area on a female's bark. Even though a female was not nearby, three males exhibited sideways gaiting, wing fanning, and backward movement, while two others only displayed a higher level of activity. All five males were active, and each found a female about 10 minutes after introduction to the female's bark.

A female had to raise the anterior part of her body for a male to be able to fit beneath her. Females always assumed a characteristic appearance for this purpose that $I$ here term the receptive posture. In the receptive posture, the fore- and midlegs were moderately extended, the hindlegs were slightly extended, and the antennae were swept back along a female's body (Fig. 2b). Most (83.3\%) females assumed the receptive posture when males touched them with their antennae (Table $1, \mathrm{C})$. Some $(15.6 \%)$ females assumed the receptive posture when males performed the sideways gait. One female waited until a male was backing underneath her.

Females assuming the receptive posture early in courtship (i.e., before antennal contact was made by a male) elicited less wing fanning from males. Males exhibited all of the actions involved in courtship, but performed them more rapidly. On the other hand, the female not assuming the receptive posture until a male began to move beneath her did not appear to inhibit the male from courting normally.

After a courtship failed, a male often fanned his wings around a female for a longer period of time during the next one, regardless of whether a female assumed the receptive posture when a male was approaching or courting $(\mathrm{N}=10)$. These prolonged courtships always led to copulation.

A male had to crouch slightly just prior to moving beneath a female, even though she had assumed the receptive posture. This position is shown in Figure 2a. Males remaining in a standing position were blocked from moving past the coxae of the females' legs $(\mathrm{N}=2)$. Furthermore, at this time a male's abdomen became slightly arched along its length, raising the posterior end.

A male's wings were kept extended over his body as he backed underneath a female, and she rested her fore- and midlegs on him. When the genitalia of a pair were apposed, the head of a female was positioned between and slightly caudad of a male's raised hindwings.

As a male moved under a female, the shelf of his epiproct, which normally rested in a posterodorsal position, struck a female's sterna 


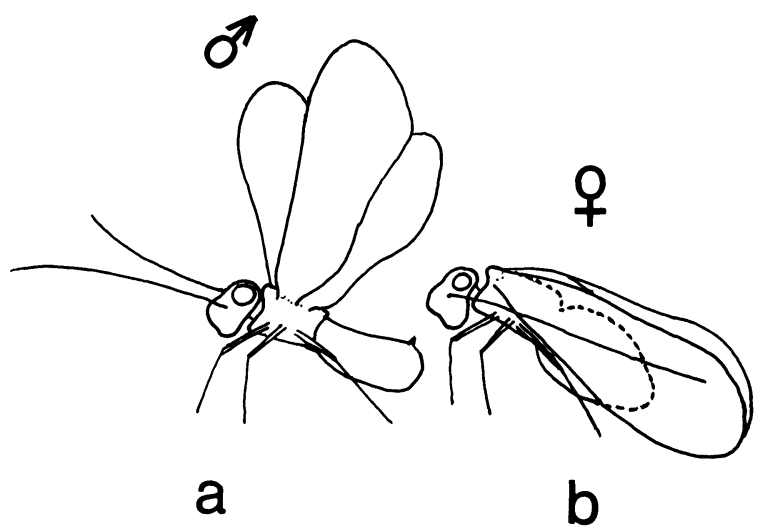

Figure 2. Typical precopulatory behavior in Trichadenotecnum alexanderae. a: A male in position to move beneath a female. b. The receptive posture of a female.

and was brought anteriorly. This flattened the shelf against the male's abdominal terga, and caused his paraprocts to extend slightly posteriorly. When fully beneath a female, a male's epiproctal shelf was brought into apposition with the basal arms of a female's subgenital plate and the sterna of her posterior abdomen.

I studied how males orient themselves with females to produce a successful mounting. Individual females $(\mathrm{N}=18)$ that had been freshly killed (by pressure from a forceps) from a Lake of the Woods culture were placed in a standing position on the substrate. Males always courted and mounted the females without losing orientation $(\mathrm{N}=5)$. When $\mathrm{I}$ reoriented a female while a male was turning around after touching her with his antennae, he did not reorient to mount successfully $(\mathrm{N}=3)$. If a female was moved as a male approached (that is, prior to antennal contact), a male was always able to orient and mount in the proper direction $(\mathrm{N}=10)$. Hence, antennal contact by males appeared to be important for a successful mounting.

When I placed a teneral male with a receptive female $(\mathrm{N}=1)$, he ran to her, paused briefly at her side, but then did not exhibit any other courting behavior (e.g., antennal contact, wing fanning, etc.). Instead, he repeatedly climbed over her for about 10 seconds until she fled. The male made no attempt to mount, and the female did not assume the receptive posture. 


\section{Copulatory Behavior}

When a male was fully beneath a female, the posterior end of his abdomen probed for hers. The valvulae of a female dropped ventrally somewhat, and moved until contact was made with a male. The genitalia of male and female $T$. alexanderae interlocked strongly together during copulation.

When their genitalia became locked, a male lifted a female off the substrate by extending his legs, which were still crouched from backing beneath her.

A normal copulatory position for a pair of $T$. alexanderae is shown in Figure 3. The hind legs of most $(67.8 \%)$ males were extended slightly more than the other pairs of legs, causing a male's head to be lowered, and raising and slightly arching his abdomen (Table 2, A). Males greatly extending their hindlegs usually also had greatly arched abdomens; males extending all pairs of legs about

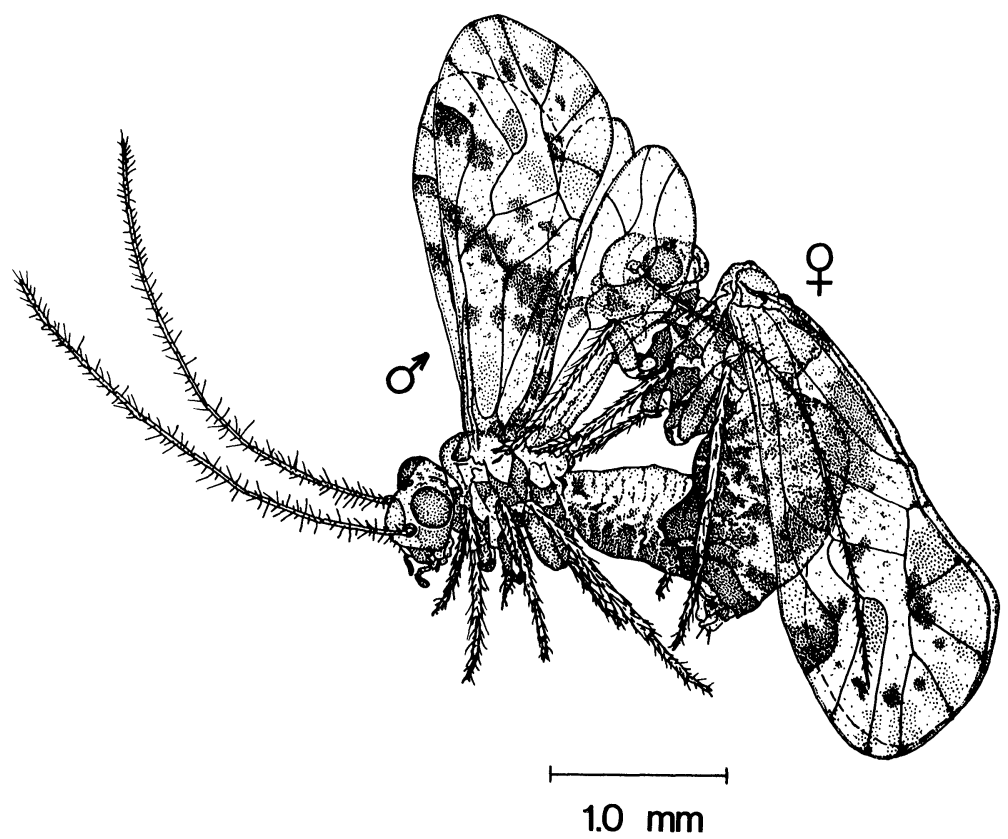

Figure 3. Trichadenotecnum alexanderae in copulation. 
equally had no abdominal arch. Because the degree of abdominal arching and the extension of the legs compensated for each other, the overall position of a male, and thus the relative positions of a male and female, generally differed little among the matings I observed. A male's abdomen became slightly more arched and his head dropped lower as copulation progressed. Some males lowered their heads so much during copulation that their maxillary palps touched the substrate.

After a female was raised off the substrate, a male's abdomen contracted more or less rhythmically. A female contracted her abdomen in synchrony with a male. Her paraprocts were periodically flexed medially during copulation.

At the beginning of copulation, the wing pairs of a male were usually extended high over his body, forming a small angle between them (Table 2, B). As copulation progressed, the angle formed by the wing pairs increased; the angle of the wings at the end of copulation was about $60^{\circ}$ greater (Table 2, C). I found $45.7 \%$ of all males had both wing pairs locked at the nodus (Table 2, D). Wing pairs remaining free were in a position as though they were locked, and thus did not interfere with copulation.

Table 2 ( $E$ and $F$ ) shows that a male's antennae generally remained in a normal resting position during copulation.

A female was lifted off the substrate until the angle formed by her body and the substrate was about $31^{\circ}-60^{\circ}$ (Table 2, G). Females whose bodies inclined more than $60^{\circ}(7.4 \%)$ had been pushed up into this position when males mounted beneath them.

A female placed her fore- and midlegs on a male when he moved beneath her. Table 2 ( $\mathrm{H}$ and $\mathrm{I})$ shows the distribution of the placement of a female's fore- and midlegs, respectively. Most (41.3\%) forelegs were placed on males' hind wings and most (50.0\%) midlegs were placed on males' anterior abdominal pleura. However, as reflected in Table 2, the first two pairs of legs were positioned in many other ways.

Table $2(\mathrm{~J})$ shows the distribution of the placement of a female's hindlegs. Most (93.3\%) females kept their hindlegs on the substrate. The rigidity of the hindlegs indicated that they were supporting some of a female's weight.

The forewing tips rested lightly on the substrate in $84.8 \%$ of the females (Table 2, K). This contact did not appear to support much of a female's weight. 
Table 2. Copulatory behavior in Trichadenotecnum alexanderae

$\%$ of Total

Position of a male

A. Extent of the arch of the abdomen

1. Not arched 21.9

2. Slightly arched $\quad 67.8$

3. Greatly arched $\quad 10.3$

$\mathrm{N}=87 \quad 100.0$

B. Angle formed by the forewings at the beginning of mating

\begin{tabular}{lr} 
1. $0^{\circ}-30^{\circ}$ & 52.3 \\
2. $31^{\circ}-60^{\circ}$ & 38.5 \\
3. $61^{\circ}-90^{\circ}$ & 6.1 \\
4. $91^{\circ}-120^{\circ}$ & 3.1 \\
\hline$N=65$ & 100.0
\end{tabular}

C. Angle formed by the forewings at the end of mating

1. $0^{\circ}-30^{\circ} \quad 5.6$

2. $31^{\circ}-60^{\circ} \quad 11.1$

3. $61^{\circ}-90^{\circ} \quad 37.0$

4. $91^{\circ}-120^{\circ} \quad 40.7$

5. $121^{\circ}-150^{\circ} \quad 0.0$

6. $151^{\circ}-180^{\circ} \quad 3.7$

\begin{tabular}{lr} 
7. $181^{\circ}-210^{\circ}$ & 1.9 \\
\hline $\mathrm{N}=54$ & 100.0
\end{tabular}

D. Number of wing pairs locked at the nodus

\begin{tabular}{lr} 
1. None & 35.7 \\
2. One & 18.6 \\
3. Both & 45.7 \\
\hline $\mathrm{N}=70$ & 100.0
\end{tabular}

E. Angle formed by the antennae

1. $0^{\circ}-30^{\circ} \quad 5.2$

2. $31^{\circ}-60^{\circ} \quad 32.8$

3. $61^{\circ}-90^{\circ} \quad 56.9$

4. $91^{\circ}-120^{\circ} \quad 3.4$

5. $121^{\circ}-150^{\circ} \quad 0.0$

\begin{tabular}{lr} 
6. $151^{\circ}-180^{\circ}$ & 1.7 \\
\hline$N=58$ & 100.0
\end{tabular}

F. Angle formed by the antennae and the bark substrate

\begin{tabular}{lr} 
1. $0^{\circ}-30^{\circ}$ & 40.5 \\
2. $31^{\circ}-60^{\circ}$ & 59.5 \\
\hline$N=74$ & 100.0
\end{tabular}


Table 2. (continued)

Position of a female

$\%$ of Total

G. Angle formed by the body of a female and the bark substrate

\begin{tabular}{|c|c|}
\hline 1. $0^{\circ}-30^{\circ}$ & 1.90 \\
\hline 2. $31^{\circ}-60^{\circ}$ & 90.7 \\
\hline 3. $61^{\circ}-90^{\circ}$ & 7.4 \\
\hline $\mathrm{N}=54$ & 100.0 \\
\hline 1. Forewing & 5.6 \\
\hline 2. Base of forewing & 29.1 \\
\hline 3. Hindwing & 41.3 \\
\hline 4. Base of hindwing & 3.1 \\
\hline 5. Metanotum & 8.7 \\
\hline $\begin{array}{l}\text { 6. Anterior abdominal } \\
\text { terga }\end{array}$ & 6.6 \\
\hline $\begin{array}{l}\text { 7. Anterior abdominal } \\
\text { pleura }\end{array}$ & 4.6 \\
\hline 8. Hind tibia & 1.0 \\
\hline$N=196^{a}$ & 100.0 \\
\hline
\end{tabular}

I. Placement of a midleg on a male

1. Hindwing 3.7

2. Hindwing base

3. Metanotum 17.7

4. Anterior abdominal terga

5. Anterior abdominal pleura

6. Anterior abdominal sterna

7. Hind tibia

8. Hind femur

9. Bark substrate 4.7 $\mathrm{N}=192^{\mathrm{a}}$

J. Placement of a hindleg on a male

1. Anterior abdominal pleura

2. Anterior abdominal sterna

3. Hind tibia

4. Bark substrate 
Table 2. (continued)

Position of a female

$\%$ of Total

K. Position of the forewing tips

1. On the bark substrate 84.8

2. In the air 15.2

$\mathrm{N}=92 \quad 100.0$

L. Angle formed by the antennae

1. $0^{\circ}-30^{\circ} \quad 25.0$

2. $31^{\circ}-60^{\circ} \quad 51.7$

3. $61^{\circ}-90^{\circ} \quad 18.3$

\begin{tabular}{lr} 
4. $91^{\circ}-120^{\circ}$ & 5.0 \\
\hline $\mathrm{N}=60$ & 100.0
\end{tabular}

M. Angle formed by the antennae and the bark substrate

\begin{tabular}{lr} 
1. $0^{\circ}-30^{\circ}$ & 88.3 \\
2. $31^{\circ}-60^{\circ}$ & 11.7 \\
\hline $\mathrm{N}=60$ & 100.0
\end{tabular}

General Features

N. Relative positions of a male and female

1. Both in-line 55.3

2. Female skewed right or left 44.7

\begin{tabular}{lr}
$\mathrm{N}=47$ & 44.7 \\
\hline 100.0
\end{tabular}

O. Duration of copulation

$\begin{array}{ll}\overline{\mathrm{X}} & 14.3 \text { minutes } \\ \text { s.d. } & 2.2 \\ \text { range } & 8.3-19.9 \text { minutes } \\ \mathrm{N} & 99\end{array}$

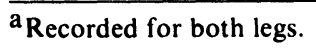

In contrast to the position of a male's antennae, a female's antennae were swept back along her body when she assumed the receptive posture. Usually the antennae were held close to her sides, and the angle formed by the antennae was between $31^{\circ}-60^{\circ}$ (Table $2, \mathrm{~L}$ ). Most (88.3\%) antennal pairs were slightly raised from the substrate (Table 2, M).

Copulation did not always proceed uneventfully. The number of positions among the pairs reflects the incidence of minor problems that were encountered during mating. The conformations occurring 
with lower frequency were usually the result of some difficulty during copulation. The relative positioning of a male and female (Table $2, N)$ generally indicates whether a problem occurred during copulation. If the bodies of a male and female were in-line, copulation usually had proceeded normally. A female was skewed left or right in $44.7 \%$ of the matings. Some of the complications that occurred during mating are discussed below.

Sometimes a male lifted a female far off the substrate, so her head was almost over his. Other males pushed females backward during mounting, then locked genitalia, causing females to be inclined almost vertically and males to have greatly arched abdomens. When events such as these occurred, the positioning of a pair, especially a female's legs, changed to maintain her balance. For example, the hindlegs of a female typically rested on the substrate. However, when a male lifted a female relatively far off the substrate, copulation proceeded with more stability when her hindlegs were placed on a male's abdomen. When a male's abdominal contractions increased to an amplitude that caused his hindwings to strike a female on the head, she placed one $(\mathrm{N}=8)$ or both $(\mathrm{N}=3)$ forelegs about midway up on a male's fore- or hindwings. This response lessened the force of a male's contractions. Sometimes a mating pair fell on their sides $(\mathrm{N}=3)$, but their genitalia remained locked. These pairs never regained a normal copulatory position, yet they did not break off copulation because of this problem.

Except for the abdominal contractions and adjustments for stability, other movements by a mating pair were uncommon. Occasionally the maxillary palps of a male or a female moved or pulsed rapidly.

I observed courtship and mating on a vertical bark substrate in the laboratory $(\mathrm{N}=3)$. When a male courted a female, she oriented herself so her head faced downward, then she assumed the receptive posture. A male lifted a female off a vertical substrate during copulation. A female was positioned dorsally and posteriorly on a male, similar to mating on a horizontal surface, but in a vertical orientation a female balanced directly above a male. On a vertical substrate the fore- and midlegs appeared to have supported more of a female's weight.

The duration of copulation varied considerably (Table 2, O), although it was never less than eight or more than 20 minutes. 


\section{Postcopulatory Behavior}

The final stage of copulation was indicated by a slowing of the rate of abdominal contractions and by contractions of a slightly more spasmodic nature. Males suddenly became active and broke off copulation (Table 3, A) by quickly running forward, dragging along the females for about 1 second until their genitalia unlocked. Of the 60 pairs I observed for this behavioral character, only two females $(3.3 \%)$ appeared to break off copulation. In each of these matings, the female became active during copulation and tried to dismount laterally, but her genitalia were locked with the male's and this caused her to fall on her side. One female successfully dismounted, thus terminating copulation. The other female failed to dismount, and instead tried to assume a normal mating position three times, but because the genitalia were locked she was kept off-balance. Copulation continued with the female supported tenuously off a side of the male.

A spermatophore was passed in all copulations, including the one broken off by a female.

Table 3 (B) shows the reactions of males after copulation was broken off. Most (53.5\%) males ran forward about $1 \mathrm{~cm}$, then remained motionless for at least 5 minutes. Some of these males had their wings parted slightly and held laterally along their bodies, but most males brought the wings back to a normal resting position. Some (28.2\%) males were highly active after copulation, and ran over the substrate without stopping for over 5 minutes. Other $(12.7 \%)$ males broke off copulation and remained almost at the place where copulation occurred. A few (5.6\%) males courted the females they had just mated, but this always caused the females to flee.

The reactions of females after copulation (Table 3, C) were somewhat different than those of males. Most (60.0\%) females remained in the area where copulation occurred; almost all of these females spun around about $90^{\circ}$, some females spun around about $180^{\circ}$. If a female ran off, she usually ran in the direction of a male because both faced in the same direction during mating. Females that ran, even for $1 \mathrm{~cm}$, never spun around more than $90^{\circ}$.

Unless disturbed by another insect, once females stopped walking after mating they rarely moved until the contents of the spermatophore that they held had been transferred. Even the antennae did 
$\%$ of Total

A. Identity of the sex breaking off copulation

\begin{tabular}{lr} 
1. Male & 96.7 \\
2. Female & 3.3 \\
\hline $\mathrm{N}=60$ & 100.0
\end{tabular}

B. Reaction of a male after copulation was broken off

1. Ran off $(>1 \mathrm{~cm})$

2. Ran about $1 \mathrm{~cm}$, then remained still 53.5

3. Stayed in the area where mating occurred

4. Tried to court the female again 5.6 $\mathrm{N}=71$ 100.0

C. Reaction of a female after copulation was broken off

1. $\operatorname{Ran}$ off $(>1 \mathrm{~cm}) \quad 8.6$

2. Ran about $1 \mathrm{~cm}$, then remained still $\quad 31.4$

3. Stayed in the area where mating occurred 60.0

$\mathrm{N}=70$ 100.0

not change position during this time. Only one of three postcopulatory females I observed at length changed her location once, about 2 minutes after copulation, but did not move after this.

Initially, a spermatophore had an appearance of a whitish, semiopaque, hemispherical droplet, protruding between the terminalia of a female. A female manipulated her terminalia so its contents passed her genital opening. When it was first visible on a female, a spermatophore seemed adhesive and somewhat fluid in shape, allowing it to be manipulated on a female's terminalia. During the transfer of its contents, a spermatophore covering seemed to lose adhesiveness and harden, allowing a female to dispose of it easily. 
A female manipulated a spermatophore between her paraprocts and valvulae. These movements were accomplished by a rhythmical, medial flexion of the terminalia. Contractions were spaced about 1-2 seconds apart, and each contraction lasted about 1-2 seconds. The epiproct was less active in this respect; it was flexed once about every 30 seconds. Epiproctal flexion probably forced the contents of a spermatophore into a female's genital area. The abdominal contractions were pronounced for about the first 4-5 minutes after copulation, then slowly decreased in rate and intensity.

The females I observed $(\mathrm{N}=3)$ required about 10-25 minutes to transfer the contents of a spermatophore and discard it. A spermatophore either fell from a female's genital area when $\operatorname{she} \operatorname{ran}(\mathrm{N}=2)$, or a female dragged the posterior end of her abdomen along the substrate for about $1 \mathrm{~mm}$ to discard it $(\mathrm{N}=1)$. A female sometimes intermittently flexed her terminalia after a spermatophore had been discarded.

\section{Evidence for a Sex-attractant Pheromone}

The following observations present evidence indicating that the attraction of males to females of $T$. alexanderae was mediated by a pheromone. All females discussed here were unmated, receptive females from cultures of all three field localities unless noted otherwise.

Males introduced to bark bearing receptive females often became more active than when they were introduced to pieces of bark which had no exposure to receptive females. Some males became so active they flew across the gap between the pieces of bark before I could join these together. A male was usually able to find a receptive female, even though she may have remained hidden from his view. Additionally, males would court females of $T$. castum and $T$. merum, two obligatorily thelytokous species of the $T$. alexanderae species complex, if vials containing these females had previously contained receptive females of $T$. alexanderae (Betz 1983a).

Females of $T$. alexanderae which had just mated ceased rapidly to be a source of attraction to males, although males occasionally tried to court females engaged in mating. Teneral females, or females in the stage of oviposition, failed to attract males (Betz 1983c).

In one mating encounter involving a male and female from a Lake of the Woods culture, when the male was introduced into a vial 
containing the female, she deposited a clear droplet from her genital area on the bark. The droplet was absorbed rapidly. The male was highly active and quickly found the female, who was still in the area where she deposited the droplet, and mated with her. In another encounter, the female deposited a droplet about 3 minutes after a failed courtship attempt. This pair mated eventually. Another female intermittently dragged the tip of her abdomen over the substrate after the male was introduced into her vial. In two encounters, each involving a male and female from a Lake of the Woods culture, two from a Lake Dawson culture, and one from a Salt Fork culture, the male persistently courted a particular place on the female's substrate, even though she was not nearby. Eventually, after about 10 minutes, males stopped courting these areas.

I have not observed females of $T$. castum or $T$. merum depositing any type of droplet in the above manner, or observed males courting places on a substrate bearing females of $T$. castum or T. merum.

In the orientation experiment, it was important to use freshly killed females because after about 5 minutes they lost attractiveness to males. Anesthetizing females with ether $(\mathrm{N}=3)$ or carbon dioxide (from dry ice) $(\mathrm{N}=3)$ caused an immediate loss of interest by males.

From the evidence cited above it appears the females of $T$. alexanderae produce a pheromone that attracts males. It appeared to be highly volatile; a loss of mating receptivity in a female was almost immediately evident, as indicated by the lack of attractiveness to males.

The area around a female in which the pheromone was effective in attracting males was rather small, having a radius of about $1 \mathrm{~cm}$. I determined this by placing individual receptive females $(\mathrm{N}=10)$ in uncovered petri dishes (standard size), then introducing sexually active males.

\section{Discussion}

Mating behavior in T. alexanderae followed a pattern outlined by Pearman (1928) for "winged Psocids." This courtship pattern, which has since been categorized (Badonnel 1951) and further documented (Klier 1956), is the one found in most species of Psocoptera that have been studied. This pattern differs from those in other species in two details: males do not run over the dorsum of females prior to mounting, and the duration of copulation is relatively long. 
A receptive posturing by females has been noted in several other species of Psocoptera (Pearman 1928, Sommerman 1943a, 1956, Schneider 1955, Broadhead 1961). Apparently only females of $T$. alexanderae have been observed assuming the receptive posture before males began backing underneath them.

The receptive posture appeared necessary only to permit males to fit beneath females during mating. Lifting the anterior end of a female's body did not communicate a female's orientation to a male. Males courting one of the freshly-killed females always moved anteriorly along her body, even though she was not in the receptive posture. However, the contact made by a male's antennae after the sideways gait probably was important in discovering how a female was oriented because a male was unable to adjust his course to find a reoriented female after antennal contact was made. Also, males that had difficulty moving beneath females began the next courtship with wing fanning, but males not contacting females recourted with a sideways gait and antennal contact. A differential concentration of pheromone along a female's body may have informed a male of her orientation. A perpendicular approach to a female allowed maximum extension of a male's antennae along her body, thus perhaps facilitating a determination of her relative position.

I found that the receptive posture was assumed by some females of $T$. alexanderae when males approaching to court began a sideways gait. Largely auditory cues, rather than visual ones, were probably given by a male to signal his approach, thereby eliciting the receptive posture in a female. The sideways gait may cause stridulation of a male's Pearman's organs because a male approaching a female in this way never caused her to flee, even though he may have remained hidden from her view during the sideways gait.

The purpose of the females' genital movements and abdominal contractions after failed courtship is unknown. These motions were only observed in females involved in some phase of the mating process. Perhaps this action released more pheromone to attract males again.

The role of the droplets (apparently containing pheromone) which were deposited by females is also uncertain. This behavior would assist a male in locating a female only if she remained in the area where a droplet was deposited. Because the pheromone appears to be highly volatile, to have any effect on males a female probably must deposit many of these droplets during her receptive period. 
The epiproctal shelf of a male played an important role during mating in $T$. alexanderae: the shelf and a female's hindlegs on the substrate supported almost all of a female's weight. A male's epiproctal shelf and the basal arms of the subgenital plate of a female are structures apparently functioning to distribute her weight because both structures are well-sclerotized and have large surface areas.

The support given by the epiproctal shelf and the interlocking genitalia apparently increased the lateral stability of a mating pair. This can be adduced in the following observations. A mating pair had greater stability during copulation than when a male had backed fully beneath a female but before their genitalia had interlocked. Also, it was difficult for a mating pair to fall over to one side when problems in stability occurred during copulation, although once they fell regaining a normal mating position was impossible. The stability supplied by the contact between the epiproctal shelfsubgenital plate and posterior abdominal sterna, the positioning of a female's legs, and the interlocking genitalia probably also expedited the lifting of a female by a male, although the reason for the necessity of lifting a female is unknown.

\section{ACKNOWLEDGEMENTS}

I thank Dr. E. L. Mockford of Illinois State University, whose beneficial discussions about Psocoptera and review of the manuscript were greatly appreciated. I. N. Holod and D. D. Pierce assisted in the production and the typing of the manuscript, respectively.

\section{SUMmary}

Pre- through postcopulatory behavior in Trichadenotecnum alexanderae Sommerman is here quantified and discussed. Mating behavior follows a pattern described for many other species of Psocoptera, in which a male approaches a female, fans his wings over his head, and backs underneath her without running over her dorsum. Additional behavioral actions, including possible stridulation and antennal contact of a female by a male and a female assuming a receptive posture prior to mounting by a male, are believed to promote copulation. Evidence is presented for a sex-attractant pheromone produced by receptive females. 


\section{Literature Cited}

Badonnel, A. 1951. Ordre des Psocoptères. Pages 1301-1340 in Grassé, P. P., ed., Traité de Zoologie, Vol. 10, Fasc. 2. Masson et Cie., Paris.

Betz, B. W. 1983a. Systematics of the Trichadenotecnum alexanderae species complex (Psocoptera: Psocidae) based on an investigation of reproductive modes and morphology. Can. Entomol. (in press).

. 1983b. The biology of Trichadenotecnum alexanderae Sommerman (Psocoptera: Psocidae). 1. Habitat, life stages and events. Entomological News (in press).

1983c. The biology of Trichadenotecnum alexanderae Sommerman (Psocoptera: Psocidae). II. Duration of biparental and thelytokous reproductive abilities. J. Kansas Entomol. Soc. (in press).

1983d. The biology of Trichadenotecnum alexanderae Sommerman (Psocoptera: Psocidae). IV. Mechanism of genitalic coupling. J. Kansas Entomol. Soc. (in press).

Broadiead, E. 1961. The biology of Psoquilla marginepunctata (Hagen) (Corrodentia, Trogiidae). Trans. Soc. Brit. Ent. 14: 223-236.

Eertmoed, G. E. 1966. The life history of Peripsocus quadrifasciatus (Psocoptera: Peripsocidae). J. Kansas Entomol. Soc. 39: 54-65.

KLIER, E. 1956. Zur Konstruktionsmorphologie des männlichen Geschlechtsapparates der Psocopteren. Zool. Jb. (Anatomie) 75: 207-286.

MOCKFORD, E. L. 1957. Life history studies on some Florida insects of the genus Archipsocus (Psocoptera). Bull. Fla. State Mus., Biol. Sci. 1: 253-274.

1977. Asiopsocus sonorensis (Psocoptera: Asiopsocidae): A new record, augmented description, and notes on reproductive biology. Southwestern Nat. 22: 21-29.

Pearman, J. V. 1928. Biological observations on British Psocoptera. III. Sex behavior. IV. Miscellaneous. Entomologist's Mon. Mag. 64: 263-268.

SCHNEIDER, H. 1955. Vergleichende Untersuchungen über Parthenogenese und Entwicklungsrhythmen bei einheimischen Psocopteren. Biol. Zentr. 74: 273-310.

Sommerman, K. M. 1943a. Bionomics of Ectopsocus pumilis (Banks) (Corrodentia, Caeciliidae). Psyche 50: 53-64.

1943b. Bionomics of Lachesilla nubilis (Aaron) (Corrodentia, Caeciliidae). Can. Entomol. 75: 99-105.

1944. Bionomics of Amapsocus amabilis (Walsh) (Corrodentia, Psocidae). Ann. Entomol. Soc. Amer. 37: 359-364.

1956. Two new species of Rhyopsocus (Psocoptera) from the U.S.A., with notes on the bionomics of one household species. J. Wash. Acad. Sci. 46: 145-149.

Thornton, I. W. B., and E. Broadhead. 1954. The British species of Elipsocus Hagen (Corrodentia, Mesopsocidae). J. Soc. Br. Ent. 5: 47-64. 

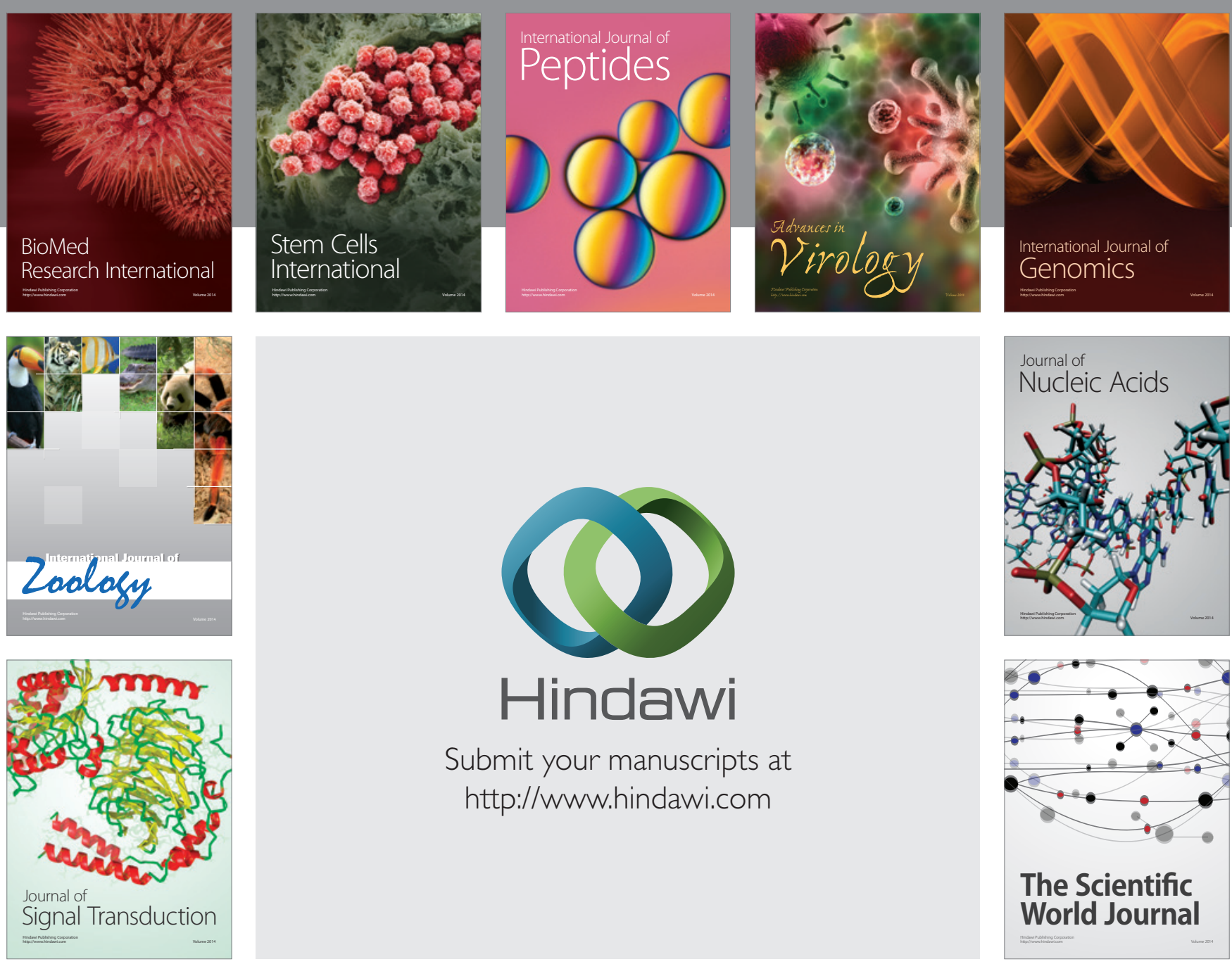

Submit your manuscripts at

http://www.hindawi.com
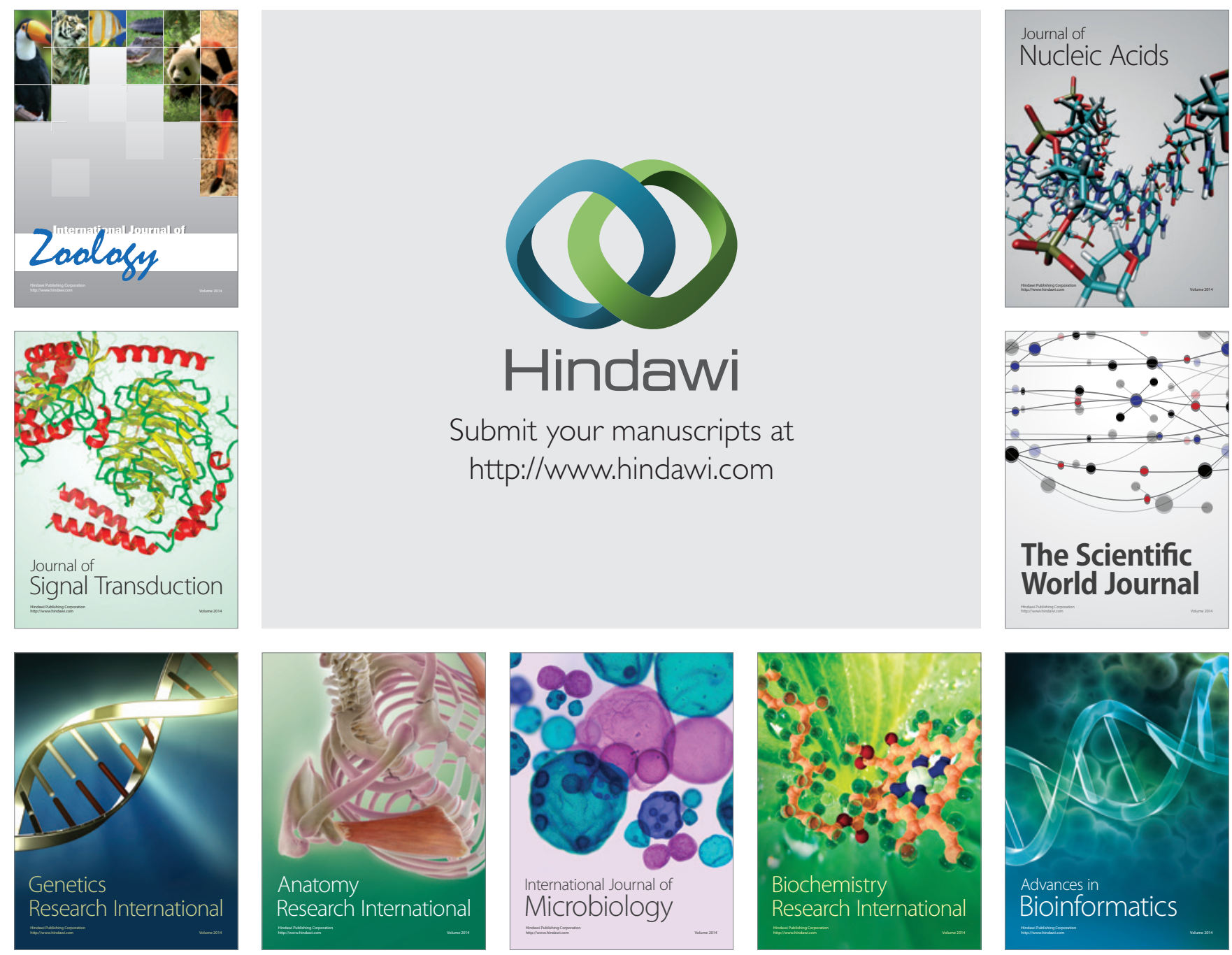

The Scientific World Journal
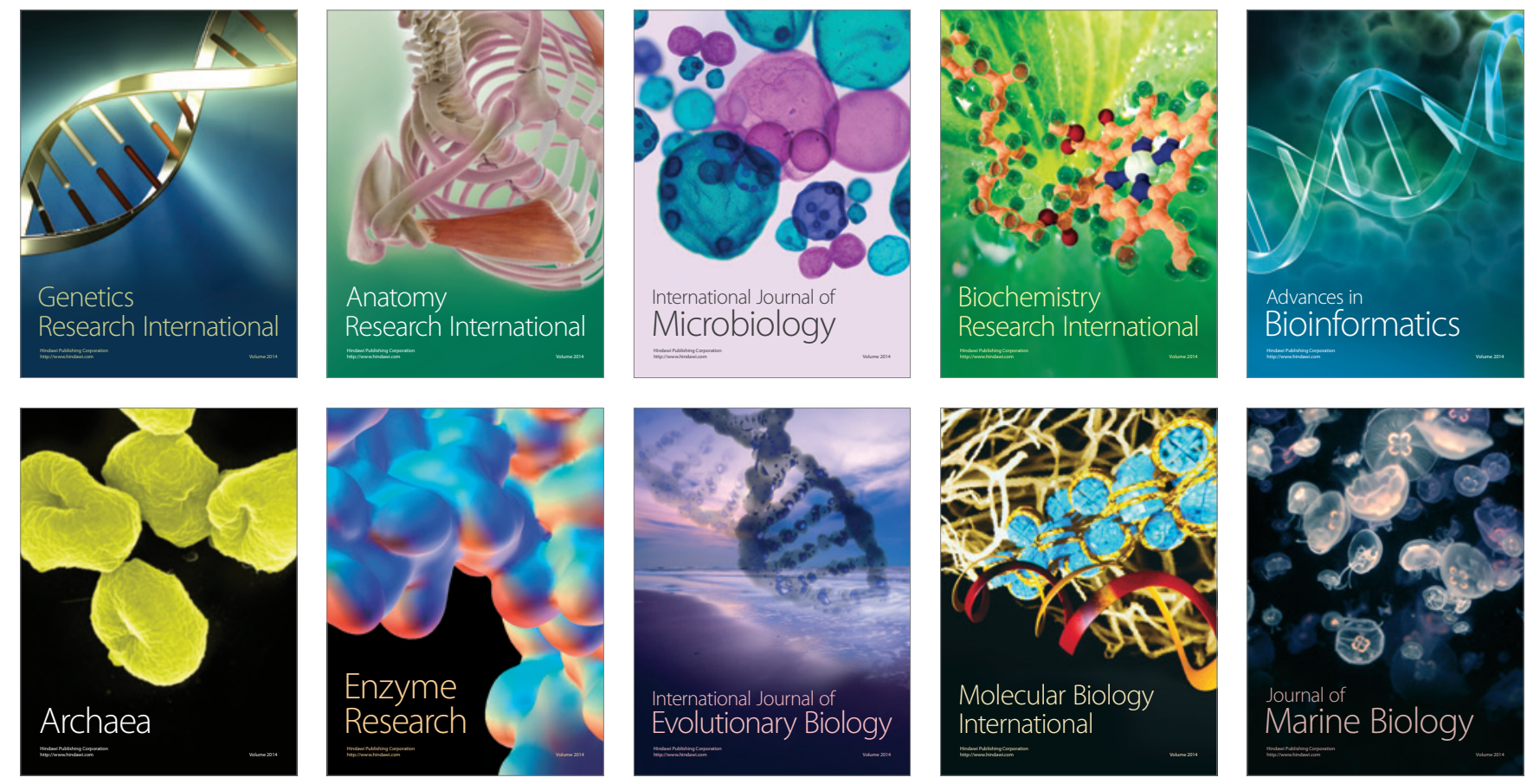